\title{
Structural analysis of fungal cerebrosides
}

\author{
Eliana Barreto-Bergter ${ }^{1}{ }^{*}$, Guilherme L. Sassaki ${ }^{2}$ and Lauro M. de Souza ${ }^{2}$ \\ Instituto de Microbiologia Paulo de Góes, Universidade Federal do Rio de Janeiro, Rio de Janeiro, Brazil \\ ${ }^{2}$ Departamento de Bioquímica e Biologia Celular, Universidade Federal do Paraná, Curitiba, Brazil
}

\section{Edited by:}

Marcio Rodrigues, Federal University of Rio de Janeiro, Brazil

\section{Reviewed by:}

Karin Thevissen, Catholic University of Leuven, Belgium

Steven Bruce Levery, University of Copenhagen, Denmark

\section{*Correspondence:}

Eliana Barreto-Bergter, Instituto de Microbiologia, Universidade Federal do Rio de Janeiro, Avenida Carlos Chagas Filho, 373, Bloco I, 21941-902

Rio de Janeiro, Brazil.

e-mail: eliana.bergter@micro.ufrj.br
Of the ceramide monohexosides (CMHs), gluco- and galactosyl-ceramides are the main neutral glycosphingolipids expressed in fungal cells. Their structural determination is greatly dependent on the use of mass spectrometric techniques, including fast atom bombardment-mass spectrometry, electrospray ionization, and energy collision-induced dissociation mass spectrometry. Nuclear magnetic resonance has also been used successfully. Such a combination of techniques, combined with classical analytical separation, such as high-performance thin layer chromatography and column chromatography, has led to the structural elucidation of a great number of fungal $\mathrm{CMHs}$. The structure of fungal $\mathrm{CMH}$ is conserved among fungal species and consists of a glucose or galactose residue attached to a ceramide moiety containing 9-methyl-4,8-sphingadienine with an amidic linkage to hydroxylated fatty acids, most commonly having 16 or 18 carbon atoms and unsaturation between $\mathrm{C}-3$ and $\mathrm{C}-4$. Along with their unique structural characteristics, fungal $\mathrm{CMHs}$ have a peculiar subcellular distribution and striking biological properties. Fungal cerebrosides were also characterized as antigenic molecules directly or indirectly involved in cell growth or differentiation in Schizophyllum commune, Cryptococcus neoformans, Pseudallescheria boydii, Candida albicans, Aspergillus nidulans, Aspergillus fumigatus, and Colletotrichum gloeosporioides. Besides classical techniques for cerebroside $(\mathrm{CMH})$ analysis, we now describe new approaches, combining conventional thin layer chromatography and mass spectrometry, as well as emerging technologies for subcellular localization and distribution of glycosphingolipids by secondary ion mass spectrometry and imaging matrix-assisted laser desorption ionization time-of-flight.

Keywords: cerebrosides, pathogenic fungi, structural characterization, mass spectrometry, NMR spectroscopy

\section{INTRODUCTION}

Cerebrosides are commonly called monohexosylceramides or ceramide monohexosides $(\mathrm{CMH})$. They are neutral glycosphingolipids that usually contain glucose or galactose, with $\beta$-glycosidic linkages to the primary alcohol of an $N$-acyl sphingoid base (ceramide). Cerebrosides can be found in plants, fungi, and animals, although clear differences in the structure of the ceramide backbone of these organisms are observed. Galactosylceramide is present only in fungi and animals. In contrast, glucosylceramide is the unique glycosphingolipid which plants, fungi, and animals have in common. CMHs have been widely detected in fungal cells (reviewed by Warnecke and Heinz, 2003; BarretoBergter et al., 2004). The current literature indicates that cerebrosides seem to be present in almost all fungal species studied so far, with Saccharomyces cerevisiae representing a well-known exception together with Candida glabrata (Tavares et al., 2008). Gluco- and galactosyl-ceramides are the main neutral glycosphingolipids expressed in fungal pathogens (Figure 1). The long-chain base (LCB) 9-methyl-4,8-sphingadienine is present in almost all pathogenic fungi studied (Levery et al., 2000; Barreto-Bergter et al., 2004). Structural modifications of the ceramide moiety in these CMHs include different sites of unsaturation as well as varying lengths of fatty acid residues. LCB was first described in monohexosylceramides from Aspergillus oryzae (Fujino and Ohnishi, 1976) and was subsequently isolated from Schizophyllum commune (Kawai and Ikeda, 1985), from the plant pathogen Fusicoccum amygdale (Ballio et al., 1979), and the edible fungi Clitocybe geotropa and Clitocybe nebularis (Fogedal et al., 1986). $\mathrm{CMHs}$ were further characterized in lipid extracts from the fungal species Alternaria raphani (Wang et al., 2009), Aspergillus fumigatus (Boas et al., 1994; Toledo et al., 1999), Aspergillus nidulans (Levery et al., 2002), Aspergillus niger (Levery et al., 2000; Levery, 2005), Aspergillus versicolor (Boas et al., 1994), Acremonium chrysogenum (Sakaki et al., 2001), Amanita muscaria (Weiss and Stiller, 1972), Candida albicans (Matsubara et al., 1987), Candida deformans (Mineki et al., 1994), Candida utilis (Wagner and Zofcsik, 1966), Colletotrichum gloeosporioides (da Silva et al., 2004), Cryptococcus neoformans (Rodrigues et al., 2000), Fonsecaea pedrosoi (Nimrichter et al., 2004), Fusarium graminearum (Zaüner et al., 2008), Fusarium solani (Duarte et al., 1998), Ganoderma lucidum (Mizushina et al., 1998), Hansenula anomala (Ng and Laneelle, 1977), Histoplasma capsulatum (Toledo et al., 2001), Hypsizygus marmoreus (Sawabe et al., 1994), Kluyveromyces waltii (Takakuwa et al., 2002), Kluyveromyces thermotolerans (Takakuwa et al., 2002), Kluyveromyces lactis (Takakuwa et al., 2002), Lentinus edodes (Kawai, 1989), Magnaporthe grisea (Koga et al., 1998; Umemura et al., 2000; Maciel et al., 2002), Mortierella alpina (Batrakov et al., 2002), Metrilium senile (Karlsson et al., 1979), Neurospora crassa (Lester et al., 1974; Park et al., 2005), Paracoccidioides brasilensis (Takahashi et al., 1996), Penicillium chrysogenum 


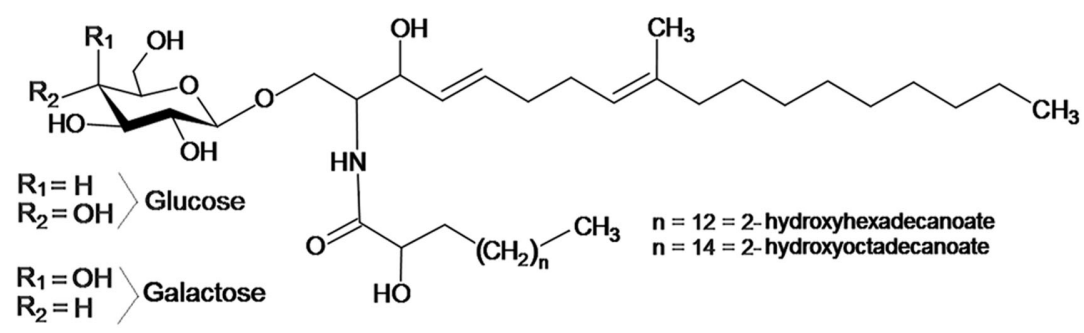

FIGURE 1 |Typical fungal cerebroside structure, containing a $\mathrm{C} 19$ sphingoid base with a $\mathrm{C}-9$ methyl group, and two double bonds ( $\Delta 4, \Delta 8$ ).

(Peng et al., 2011), Pichia pastoris (Sakaki et al., 2001), Polyporus ellisii (Gao et al., 2001), Polyporus squamosus (Arigi et al., 2007), Pseudallescheria boydii (Pinto et al., 2002), Rhynchosporium secalis (Sakaki et al., 2001), Saccharomyces kluyveri (Takakuwa et al., 2002), Sordaria macrospore (Sakaki et al., 2001), Sporothrix schenckii (Toledo et al., 2000), Termitomyces albuminosus (Qi et al., 2001), Zygosaccharomyces cidri, and Zygosaccharomyces fermentati (Takakuwa et al., 2002).

Whereas many studies have focused on the functional roles of glycosphingolipids in mammals, relatively little is known about the structures of glycosphingolipids of pathogenic organisms, and how such pathogen-derived glycosphingolipids influence immune functions of their hosts.

CMHs have been characterized in fungal cells as bioactive molecules with several distinct roles. Fungal cerebrosides induce cell differentiation in S. commune, and the $8 \mathrm{E}$-double bond and the methyl group at C-9 in the sphingoid base is essential for this differentiation (Kawai and Ikeda, 1982). Monohexosylceramides isolated from the rice pathogen $M$. grisea are active elicitors of the hypersensitive response in rice (Koga et al., 1998; Umemura et al., 2000).

The presence of $\mathrm{CMH}$ as a structural component of the fungal cell wall was clearly demonstrated by electron microscopy of yeast cells of $C$. neoformans labeled with immunogold antibodies (Rodrigues et al., 2000) and by immunofluorescence of mycelium cells of C. gloeosporioides, using a monoclonal antibody to GlcCer (da Silva et al., 2004). Glucosylceramides from P. boydii, accumulated on the surface of mycelia and pseudo-hyphal forms, were recognized by antibodies from rabbits immunized with $P$. boydii whole cells (Pinto et al., 2002).

A monoclonal antibody to the glucosylceramide synthesized by $P$. brasiliensis was produced and reacted with $A$. fumigatus conidiophore. This finding supported the idea that CMHs are preferentially accumulated on surface sites related to fungal growth, but it also suggested that they are involved in the differentiation process (Toledo et al., 2001).

Using polyclonal antibodies or Mabs anti-monohexosylcera mides, our group showed that CMHs were associated with fungal growth (Rodrigues et al., 2000; Nimrichter et al., 2005) and morphological transitions in C. neoformans, P. boydii, C. albicans, A. fumigatus, C. gloeosporioides, and S. apiospermum (reviewed by Barreto-Bergter et al., 2004).

We now describe methods to extract neutral glycosphingolipids (GSLs) from fungal cells, techniques to separate them by thin-layer chromatography (TLC) or high-performance thin layer chromatography (HPTLC) and, finally, strategies to structurally characterize the glycan and ceramide moieties of the GSLs.

\section{ISOLATION AND PURIFICATION}

The methodology described herein follows the steps of purification routinely used in our laboratory for $\mathrm{CMH}$ extraction and purification (Boas et al., 1994; Duarte et al., 1998, Pinto et al., 2002; da Silva et al., 2004), although different methods are available in the current literature for isolation and purification of $\mathrm{CMHs}$ (reviewed by Barreto-Bergter et al., 2004).

Fungal cells are successively extracted with chloroformmethanol (2:1 and 1:2 v/v). Extracts are combined, dried, and the crude lipid extract is partitioned according to (Folch et al., 1957). The lipids recovered from the Folch lower layer are fractionated on a silica gel column eluted with chloroform, acetone, and then methanol. The acetone and methanol fractions containing CMHs are further purified on a silica gel column, which are sequentially eluted with chloroform-methanol with increasing concentrations of methanol $(95: 5,9: 1,8: 2$, and $1: 1 \mathrm{v} / \mathrm{v})$, and finally with $100 \%$ methanol. Fractions eluted with chloroform-methanol (9:1 and $8: 2 \mathrm{v} / \mathrm{v}$ ) are further purified by chromatography on Iatrobeads RS 2060 (Macherey and Nagel, Düren, Germany), using the same elution system, to provide a purified glycosphingolipid fraction. A typical example of the purification of cerebrosides is shown in Figure 2.

\section{ANALYTICAL TECHNIQUES TO STUDY CEREBROSIDES HIGH-PERFORMANCE THIN-LAYER CHROMATOGRAPHY}

Thin-layer chromatography is a popular and convenient technique for separation and identification of $\mathrm{CMH}$, and is the first step in analysis of glycosphingolipids, requiring only small amounts (3-4 nM) of material (Scandroglio et al., 2009). This technique does not allow determination of chemical structures, but can give preliminary information on their structures based on chromatographic mobility, in comparison with standards (Wells and Dittmer, 1965; Scandroglio et al., 2009) and the reaction with specific staining reagents (Svennerholm, 1956; Scandroglio et al., 2009). Cerebrosides are analyzed on HPTLC plates developed with $\mathrm{CHCl}_{3}-\mathrm{MeOH}-\mathrm{H}_{2} \mathrm{O}(65: 25: 4 \mathrm{v} / \mathrm{v})$ or $\mathrm{CHCl}_{3}-\mathrm{MeOH}-$ $2 \mathrm{M} \mathrm{NH}_{4} \mathrm{OH}$ (40:10:1 v/v/v; Pinto et al., 2002; Rollin-Pinheiro et al., unpublished) and visualized through iodine vapor, which is absorbed by both saturated and unsaturated lipids (Kates, 1986), and by spraying the plates with orcinol-sulfuric acid, in which case cerebrosides give violet spots (Svennerholm, 1956). 


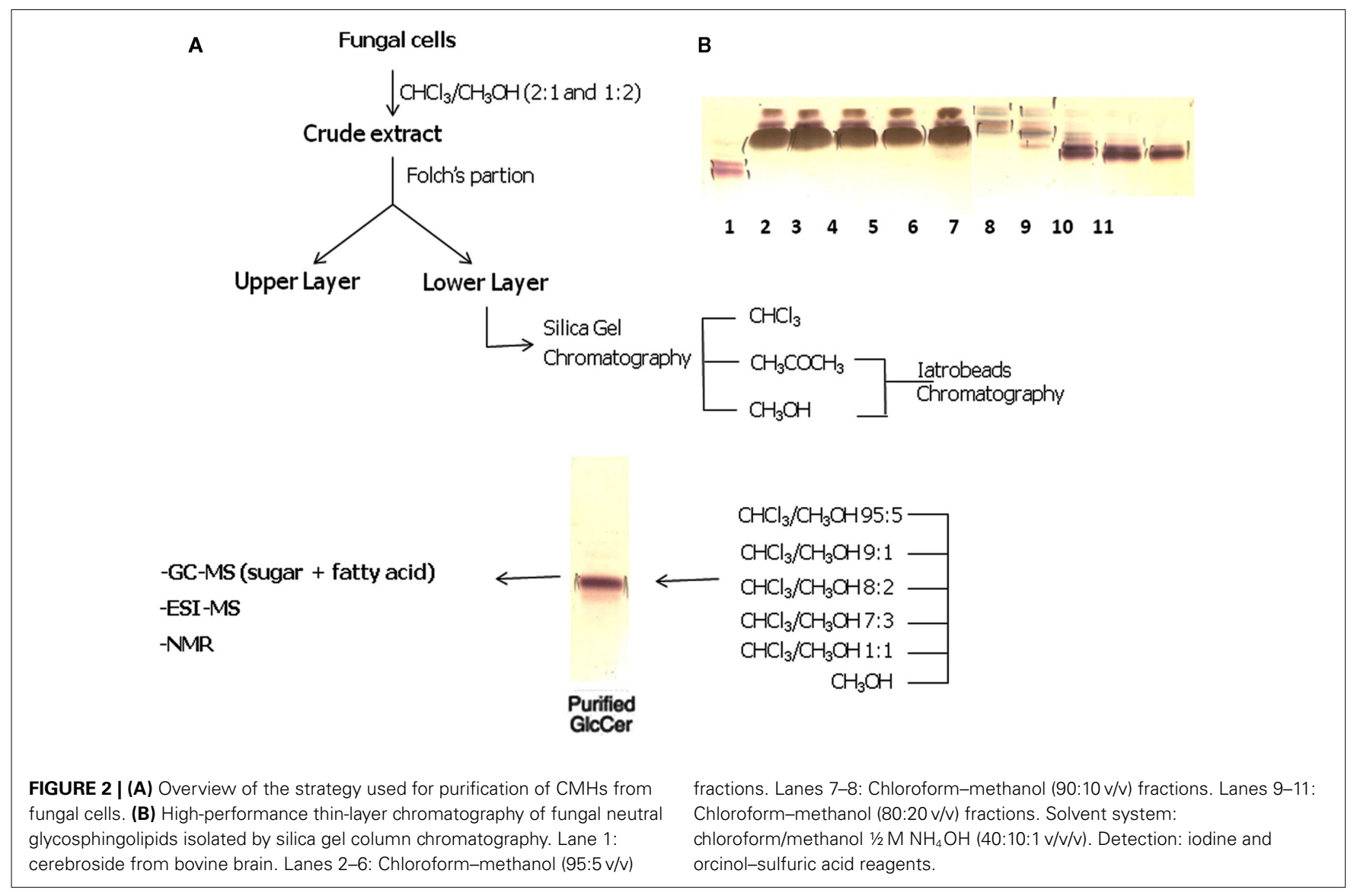

\section{MASS SPECTROMETRY APPLIED TO FUNGAL LIPID ANALYSIS}

Mass spectrometry (MS) is a powerful tool for the analysis of lipids. However, in the early days of its development, the intact lipids could not be directly analyzed by MS, since the available ionization sources produced ions by accelerating electrons electron ionization (EI), which should provide the molecules in a gaseous phase, to transfer their energy on ionization. This was the limiting factor for its application, since the molecules must have a sufficient vapor pressure to enter into the gaseous phase of the mass spectrometer's ion source. Briefly, MS with EI was coupled to gas chromatography (GC-MS) and lipids could be analyzed. However, in order to become analyzable, CMHs should be converted to their constituent moieties (sugar, fatty acids, LCB), submitted to appropriate chemical derivatization and then identified by GC-MS.

To overcome the requirements for volatilization, the glycosphingolipids were methanolyzed and their components analyzed as fatty acid methyl esters (FAMEs) (Duarte et al., 1998).

The monosaccharide components of glycosphingolipids were analyzed by GC-MS, by conversion to alditol acetate derivatives after being liberated by acid hydrolysis (Sawardeker et al., 1965). Long-chain bases were released (LCB, or sphingoid base) from $\mathrm{CMH}$ by methanolysis and analyzed by GC-MS as the TMS derivatives after treatment with bis-(trimethylsilyl) -trifluoroacetamide/pyridine (Zanetta et al., 1999; Sweeley, 1963; Karlsson and Holm, 1965). A simple derivatization method established by Sassaki et al. (2008) can also be employed for
GC-MS identification of monosaccharides and LCB, present in glycosphingolipids.

The highly energetic electrons $(70 \mathrm{eV})$ in EI produce radical ions, but a secondary effect associated with EI is an intense production of fragment-ions, due to the extensive covalent-linkage breakdown promoted by the absorbed energy by the molecules.

In order to overcome the tendency of fragmentation during the ionization process, other ion sources have been developed, called soft ionization methods.

\section{SOFT IONIZATION TECHNIQUES FOR THE DETERMINATION OF THE STRUCTURE OF INTACT LIPIDS}

The soft ionization technologies allow ionization and transferring non-volatile and thermolabile molecules to the gaseous phase without extensive production of fragments, impossible with EI. This type of source became available from 1980s with the introduction of fast atom bombardment-mass spectrometry (FAB-MS), followed by electrospray ionization mass spectrometry (ESI-MS), and matrix-assisted laser desorption ionization (MALDI). Another important characteristic is that these techniques allow changing the ion polarity, since it is possible to produce ions via cation or anion interactions, such as protonation, sodiation, lithiation or deprotonation, chlorination, and so on. Nowadays, variations of these techniques are also found, such as nano-ESI-MS, photospray ionization, as well as those called ambient MS, which include direct analysis in real time-mass spectrometry (DART-MS) and desorption electrospray (DESI), 
suitable for analysis of analytes deposited on a surface, such as with HPTLC.

The ions obtained from intact molecules provide information on their molecular weight, as well as fragmentation being an important tool for structural analysis. The MS instrumentation allow separation of a specific ion and subjecting it to a fragmentation process, as occurring in collision-induced dissociation (CID) or collision-activated dissociation (CAD). This type of analysis is usually referred to as tandem-MS and the spectrometers operating in tandem mode consist of conjugated analyzers, such as triple quadrupole (TQ or QQQ), quadrupole-time of flight (Q-TOF) or the ion trap, and Fourier-transform ion cyclotron resonance (FTICR) analyzers, which allow the re-fragmentation of product ions (fragment-ions from MS/MS) usually referred to as $\mathrm{MS}^{\mathrm{n}}$.

\section{FAST ATOM BOMBARDMENT-MASS SPECTROMETRY}

Fast atom bombardment was first introduced by (Barber et al., 1981a,b; Morris et al., 1981). The sample is dissolved in a nonvolatile liquid matrix (e.g., glycerol, thioglycerol, triethanolamine), and the mixture is bombarded by a beam of accelerated atoms (typically argon or xenon). Non-volatile, polar, and thermolabile molecules, such as lipids, could be ionized directly analyzed (Murphy et al., 1982). FAB-MS is considered to be a relatively soft ionization technique, since it produces primary the molecular ion (quasi- or pseudo-molecular ions), although numerous fragments ions are typically generated.

Since FAB-MS allowed the analysis of a broad range of intact molecules, it rapidly became one of the most commonly used techniques for structural characterization of lipids, including a wide variety of fungal cerebrosides, using native and peracetylated samples (reviewed by Levery, 2005). The structure of $A$. fumigatus $\mathrm{CMH}$ was elucidated, using FAB-MS in the positive mode (Boas et al., 1994). Spectra were obtained using peracetylated samples, in the presence and the absence of sodium acetate, and the main $\mathrm{CMH}$ from $A$. fumigatus was identified as $2^{\prime}-N$-hydroxyoctadecenoyl-1-O- $\beta$-D-glucopyranosyl-9methyl-4,8-sphingadienine. The presence of an additional ceramide containing 2-hydroxy-octadecanoic acid was reported by (Toledo et al., 1999), employing ESI-MS and ESI-MS/CID.

Using peracetylated samples with positive- and negative-ion FAB-MS, other cerebrosides were characterized by our group from A. versicolor, C. neoformans, F.pedrosoi, F. solani, Fusarium sp., and M. grisea (reviewed by Barreto-Bergter et al., 2004). FABMS analysis of native and peracetylated samples indicated that the glycolipid from $P$. boydii consisted of two components that differ in their fatty acid compositions. In a negative-ion spectrum, deprotonated molecules appeared at $\mathrm{m} / \mathrm{z} 726$ and 754, consistent with monohexosylceramides containing hydroxyl-hexadecanoic and hydroxyl-octadecanoic acids, and C19 sphingadienine. On peracetylation with acetic anhydride/pyridine, $[\mathrm{M}+\mathrm{Na}]^{+}$ions were at $\mathrm{m} / \mathrm{z} 1030$ and 1002, indicating addition of six acetyl groups to the mass of the underivatized glycolipids, consistent with hydroxyl acid-containing monohexosylceramides (Figure 3).

Over the past decades, FAB-MS/MS has been used to characterize sphingolipids, since it offers many advantages for structural elucidation and has high-energy CID capabilities (Domon and Costello, 1988; Pittenauer and Allmaier, 2009a,b; Ann and Adams, 1992; Ann and Adams, 1993). Evidence for the location of double bonds in the long-chain base was obtained by collisional activation of the sphingadienine fragments at $\mathrm{m} / z$ 276. Cleavages of the alkyl chain indicated the presence of a 4,8-sphingadienine structure, with a methyl substituent on C-9. An identical fragment ion
A

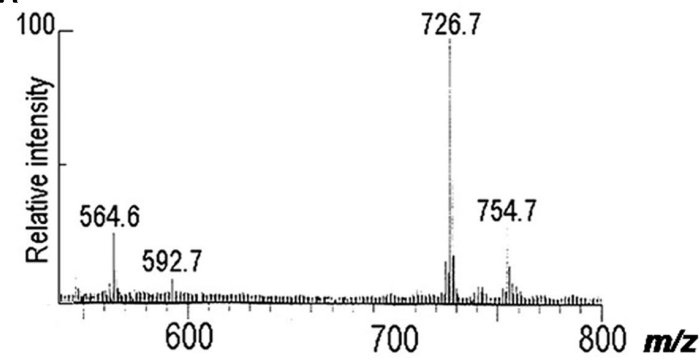

B

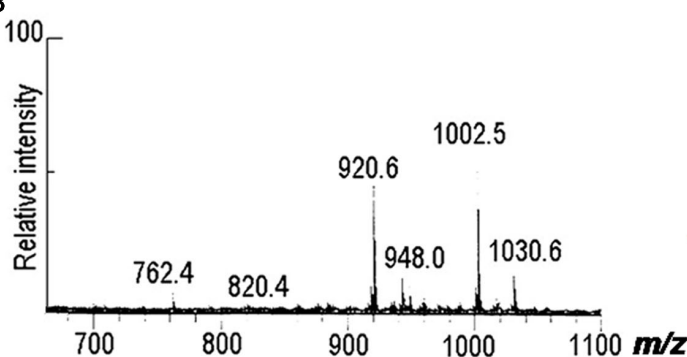

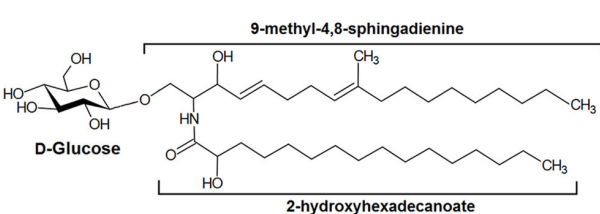
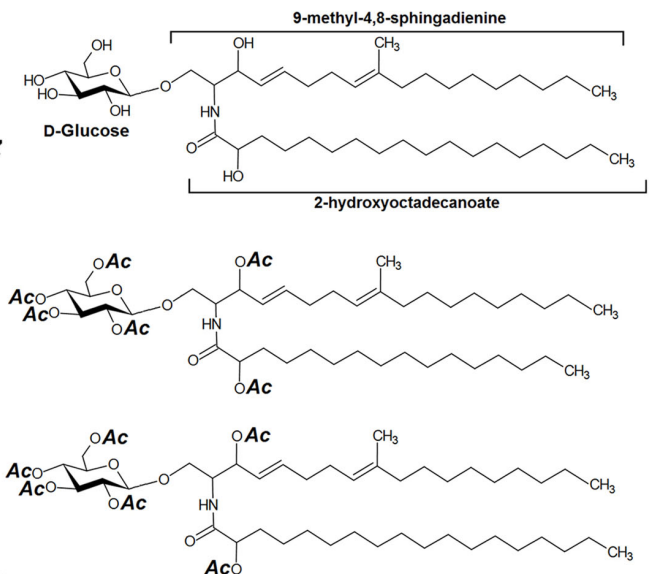

FIGURE 3 | Fast atom bombardment-mass spectrometry spectra of CMHs from $\boldsymbol{P}$. boydii. (A) Negative-ion spectrum [M - $\mathrm{H}^{-}$of native $\mathrm{CMHs}$, and (B) positive-ion spectrum $[\mathrm{M}+\mathrm{Na}]^{+}$of peracetylated $\mathrm{CMHs}$. 
spectrum was obtained from collision activation of $\mathrm{m} / z 276$ in the FAB spectrum of the CMH from F. solani (Duarte et al., 1998) and A. fumigatus (Boas et al., 1994).

\section{ELECTROSPRAY IONIZATION MASS SPECTROMETRY}

In the mid 1980s, two soft ionization techniques were developed, ESI by John Fenn (Yamashita and Fenn, 1984) and MALDI (Karas et al., 1987). These techniques allowed direct analysis by MS of a great number of lipids.

Electrospray ionization mass spectrometry is an atmospheric pressure ionization technique, in which the sample can be dissolved in common solvents, such as methanol, acetonitrile, water, or in mixtures. The sample passes through a capillary tube, to which an intense electrical field is applied creating a spray of charged particles which are dried with the aid of a nitrogen flow and the ionized analytes are transferred to mass analyzers (Yamashita and Fenn, 1984).

Matrix assisted laser desorption ionization is a desorption ionization (DI) method which deserves special attention because, besides its extraordinary sensitivity, it is efficient in producing intact molecular ions of large biological compounds. The MALDI matrix compounds are usually organic acids that have strong electronic absorption in the region of the applied laser wavelength.

Ions obtained by the soft ionization processes usually appear as protonated or deprotonated species, depending on their chemical characteristics. However, it is also common to find ions produced by the combination of the analyte with different cations or anions, such as $\mathrm{Na}^{+}$or $\mathrm{K}^{+}$and $\mathrm{Cl}^{-}$, which are referred to as adducts. These ions are commonly present in the solvent and could aid the ionization of several polar molecules, such as neutral glycolipids. On the other hand, small amounts of specific adducts (e.g., $\mathrm{Li}^{+}$) can be added to the solvent, to increase ion production.
Ions obtained from intact molecules contain information on their molecular weight, although further information is necessary to define their chemical structures. Accordingly, the majority of mass spectrometers allow the selection of a specific ion and its fragmentation. This type of analysis is usually referred to as tandem-MS (MS/MS). Spectrometers capable of performing tandem-MS consist of conjugated analyzers, such as TQ or QQQ, $\mathrm{Q}-\mathrm{TOF}$ or the ion trap analyzer.

Positive-ion mode ESI-MS employing quadrupole instruments has been used extensively for fungal cerebroside analysis (Toledo et al., 1999; Levery et al., 2000; Toledo et al., 2000; da Silva et al., 2004; Nimrichter et al., 2005). A GlcCer-enriched fraction of C. gloeosporioides was analyzed in the positive ion ESI-MS mode $[\mathrm{M}+\mathrm{H}]^{+}$. Two major ion species appeared at $m / z 754$ and 756 , as well as their corresponding fragments at $\mathrm{m} / z 736$ and 738 , generated by the loss of elements of water (Figure 4A). ESI-MS/MS has also been applied and major fragment-ions at $m / z 594$ and 592 were obtained, and assigned to $2^{\prime}-N$-hydroxyoctadecanoyl9-methyl-4,8-sphingadienine and $2^{\prime}-N$-hydroxyoctadecenoyl-9methyl-4,8-sphingadienine respectively (Figures 4B,C) (da Silva et al., 2004).

As neutral molecules, CMHs can be analyzed by MS with the aid of adducts, the most common one being $\mathrm{Na}^{+}$. However, the use of other adducts could reveal more details from the structures, by evidencing fragments which could be missed. The use of $\mathrm{Li}^{+}$, as $\mathrm{LiCl}$, or LiI, to aid cationization of neutral molecules containing carbohydrates has proven to be useful, improving ion detection and fragmentation provided by collision-induced dissociation-mass spectrometry (CID-MS), using less energies than other common alkali cations (i.e., $\mathrm{Na}^{+}$and $\mathrm{K}^{+}$). ESI-MS/CID-MS of lithium adducts was applied for analysis of cerebrosides from $F$. pedroso $i$ (Nimrichter et al., 2005), A. niger, C. albicans, Cryptococcus spp., and yeast and mycelium forms of $P$. brasiliensis (Levery et al., 2000). More recently, ESI-MS in the positive ionization mode of lithiated

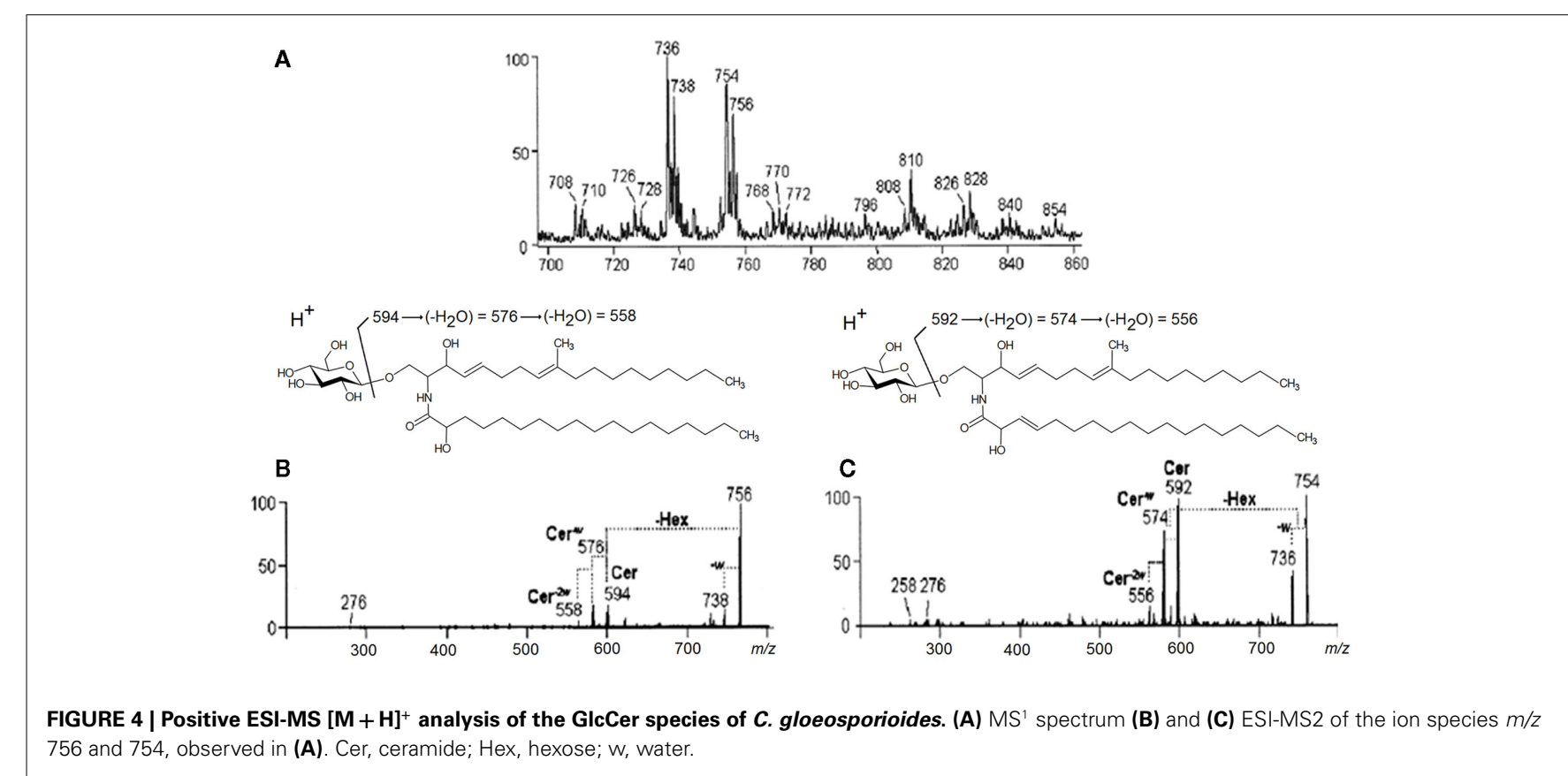




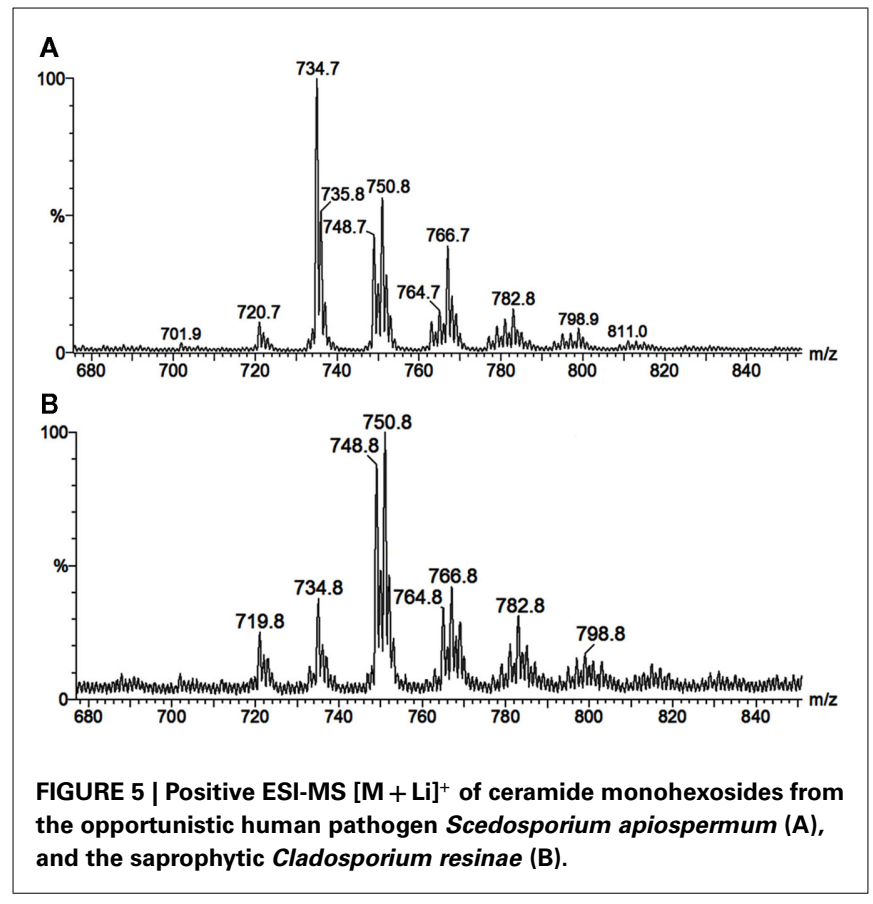

adducts has been used by our group for cerebroside analysis of $S$. apiospermum, an opportunistic human pathogen that belongs to the P. boydii/Scedosporium complex (Rollin-Pinheiro et al., unpublished). Ions with ranging from $\mathrm{m} / \mathrm{z} 700$ to 800 were detected, with two major ion species appearing at $m / z 734[\mathrm{M}+\mathrm{Li}]^{+}$and $750[\mathrm{M}+\mathrm{Li}]^{+}($Figure 5A). Although in a different ratio, similar results were found in the analysis of glycosphingolipids from Cladosporium resinae (Figure 5B), a saprophytic species commonly found as a contaminant in fuel oil storage tanks (Lindley and Heyderman, 1985; Seifert et al., 2007). CID-MS analysis confirmed their similarities and revealed that the differences were located in the LCB moieties (Figures 6A-D).

An ESI-MS examination of lipid extracts from F.pedrosoi (Nimrichter et al., 2005), another human pathogen, also showed the presence of an ion at $\mathrm{m} / \mathrm{z} 750$. This was interpreted as resulting from a ceramide with a LCB containing one more hydroxyl group. This hypothesis was supported by the analysis of the permethylated $\mathrm{CMH}$ derivative, showing a molecular, monolithiated ion at $m / z 862$, consistent with addition of eight methyl groups. Fragmentation of permethylated CMH suggested that the additional hydroxyl group is linked to C-4 or C-5 of its long-chain base (Nimrichter et al., 2005). However, this LCB conserves other characteristics of fungal LCBs, such as the presence of a double
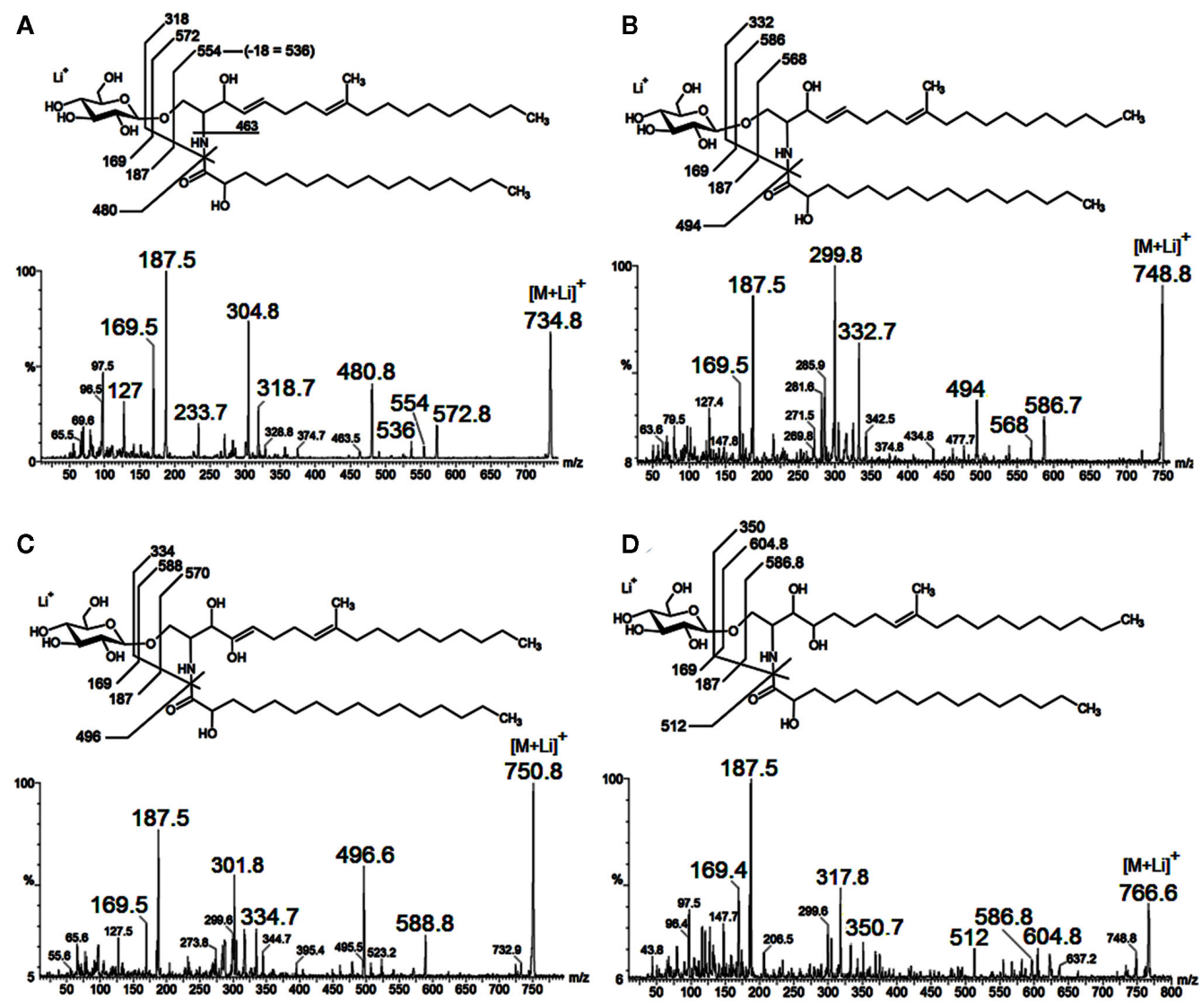

FIGURE 6 | Characteristic tandem-MS profiles obtained from lithiated CMHs from Scedosporium apiospermum $(\mathrm{A}, \mathrm{C})$ and Cladosporium

resinae (B,D). The fragmentation indicated differences in the LCB moieties and the putative structures were depicted for each $\mathrm{CMH}$ species. 
bond (C8 to $\mathrm{C}-9$ ) and a $\mathrm{CH}_{3}$ group in $\mathrm{C}$, distinguishing it from phytosphingosine.

\section{NMR SPECTROSCOPY}

Nuclear magnetic resonance (NMR) spectroscopy is a nondestructive method capable of furnishing information concerning the primary structure of cerebrosides, such as monosaccharide composition, anomeric configuration, and size of the sugar rings. The assignments of all ceramide signals could also be obtained without interference of the sugar moiety.

Fungal cerebrosides have been characterized by $1 \mathrm{D}, 2-\mathrm{D}-{ }^{1} \mathrm{H}-$ $\mathrm{NMR}$, and ${ }^{13} \mathrm{C}$-NMR spectroscopy as native (underivatized) or peracetylated samples.

Native glycosphingolipid fractions isolated from Paracoccidioides brasiliensis (Toledo et al., 1999), Aspergillus fumigatus (Toledo et al., 1999), Sporothrix schenckii (Toledo et al., 2000), Histoplasma capsulatum (Toledo et al., 2001), dissolved in DMSOd6/2\% D2O have been extensively analyzed by a series of 1and 2-D homonuclear and heteronuclear NMR experiments (1H-1H TOCSY, NOESY, ${ }^{1} \mathrm{H}_{-}{ }^{13} \mathrm{C}$ HSQC, HMBC). According to the authors, this solvent presents superior solubility characteristics as compared with $\mathrm{CDCl} 3 / \mathrm{CD} 3 \mathrm{OD}$ mixtures and chemical shift reproducibility for cerebrosides without the need for derivatization. Using these techniques, a native glycosphingolipid fraction from Fusarium oxysporum dissolved in $\mathrm{CDCl}_{3}-\mathrm{CD}_{3} \mathrm{OD}$ was recently characterized (Figure 7).

${ }^{1} \mathrm{H}$ and ${ }^{13} \mathrm{C}$-NMR spectra for several fungal glucosylceramides have been previously recorded as per- $O$-acetylated compounds in CDCl3 (Fogedal et al., 1986; Boas et al., 1994; da Silva et al., 1997; Duarte et al., 1998) and more recently in M. alpina (Batrakov et al., 2002) and F. graminearum (Zaüner et al., 2008).

In the ${ }^{1} \mathrm{H}$-NMR spectrum of the peracetylated GlcCer of $A$. fumigatus, protons corresponding to a $\beta$-glucopyranosyl unit were recognized by their characteristic chemical shifts (Boas et al., 1994). The spectrum displayed one sharp doublet at $\delta 4.47 \mathrm{ppm}$ with a coupling constant $J_{1,2}=7.9 \mathrm{~Hz}$ due to anomeric nuclei. The remaining protons appearing in the spectrum were in agreement with the $\beta$-glucopyranose structure. The structure of the longchain base was deduced from one- and two-dimensional NMR spectra. The proton to proton COSY spectrum enabled the connectivity of the long-chain base protons to be traced between $\mathrm{H}-1$ and $\mathrm{H}-11$ and those of the fatty acid from $\mathrm{H}-2$ to H-5. The chemical shifts of 5.30 and $5.50 \mathrm{ppm}$, assigned to the long-chain base $\mathrm{H}-3$ and the fatty acid $\mathrm{H}-2$, respectively, were typical of protons with acetylated $\mathrm{OH}$-groups neighboring the olefinic bonds. For $\mathrm{H}-4$ and $\mathrm{H}-5$ of the long-chain base, we found a coupling constant of $15.3 \mathrm{~Hz}$ and for the protons $\mathrm{H}-3$ and $\mathrm{H}-4$ of the fatty acid 14.3 Hz, respectively, typical of trans-double bonds. An additional

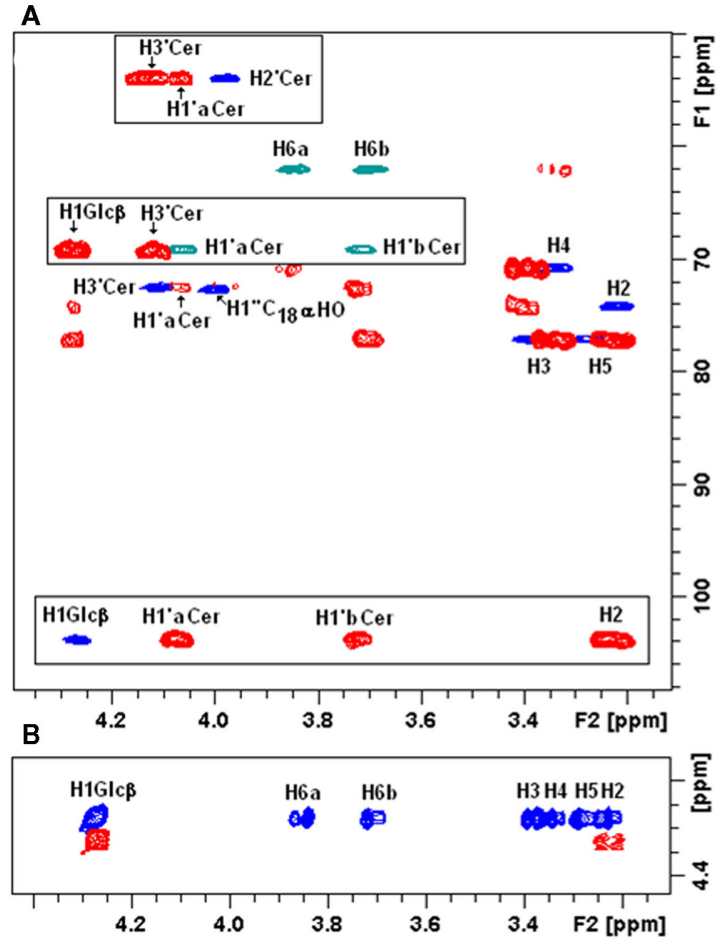

FIGURE 7 | Two-dimensional NMR fingerprints of F oxysporum $\mathrm{CMH}$ observed by homonuclear and heteronuclear experiments. (A) Overlaid representation of fingerprint assignments of partial edited HSQC and $\mathrm{HMBC}$ spectra; positive phase (blue) correspond to $\mathrm{CH}$ and $\mathrm{CH} 3$ carbons, negative phase (green) correspond to $\mathrm{CH} 2$ carbons, in (red) HMBC cross peaks; (boxes) represent glycosyl-ceramide linkage zones fingerprints. (B) Partial
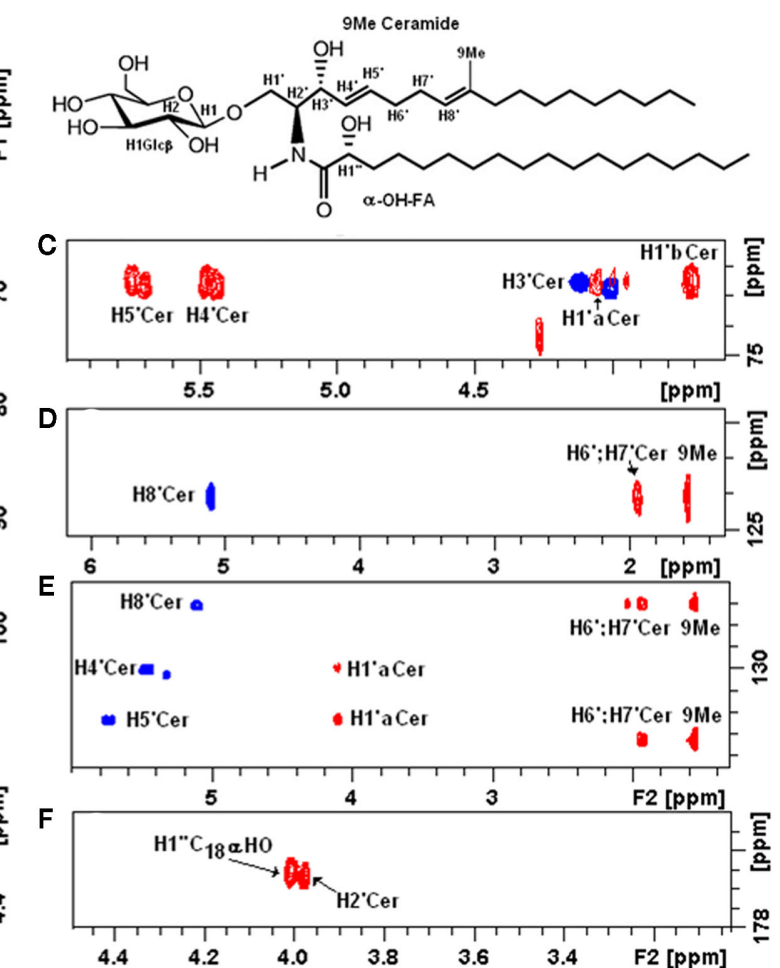

TOCSY (blue) and COZY (red) spectra from the anomeric region showing the main cross peaks of the carbohydrate ring, observation of the total ${ }^{1} \mathrm{H}-{ }^{11} \mathrm{H}$ axial correlations and reach the monosaccharide composition. (C-E) HSOC and $\mathrm{HMBC}$ slices of unsaturated carbons in ceramide moiety. (E,F) Fingerprint slices of the quaternary carbons (C-9) and amide linkage at 136.4 and $176.5 \mathrm{ppm}$, respectively. 
upfield resonance for the cerebrosides was that of the sphingadienine 9-methyl group which was a singlet at $\sim 1.545 \mathrm{ppm}$. However, the chain lengths of the fatty acid and the sphingosine moieties of GlcCer could not be determined by NMR analysis, in contrast with mass spectrometric methods (Levery, 2005).

In summary, a series of $\mathrm{CMHs}$ were isolated from pathogenic fungi and their structures elucidated using a combination of HPTLC, FAB-MS, ESI-MS spectrometry, and NMR. Their principal structures are shown in Figure 8.

\section{TLC OVERLAY TECHNIQUES}

The TLC overlay technique was introduced by Magnani et al. (1980) and consists of resolution of the glycosphingolipid on a TLC plate, with detection of the $\mathrm{CMH}$ in situ using specific ligands as antibodies, bacterial toxins, carbohydrate-specific viruses, and bacteria. Crude lipid extracts containing glycosphingolipids as minor components could also be analyzed, avoiding time consuming purification procedures. It is a highly sensitive technique that only requires nanogram quantities of $\mathrm{CMH}$ (Meisen et al., 2011).

\section{HIGH-PERFORMANCE THIN-LAYER CHROMATOGRAPHY IMMUNOSTAINING}

Using anti-glucosylceramide antibodies, $\mathrm{CMH}$ could be identified in cell wall lipid extracts of $C$. neoformans separated by HPTLC (Rodrigues et al., 2000). Using an IgG 2a monoclonal antibody anti-glucosylceramide (MEST-2), Toledo et al. (2001) showed that this Mab reacts with glucosylceramide from yeast and mycelium forms of $P$. brasiliensis, H. capsulatum, S. schenckii, hyphae of
A. fumigatus, and yeast forms of C. albicans, C. neoformans, $C$. laurentii, and C. albidus. The same results were observed using solid-phase radioimmunoassay (RIA). Studies on the specificity of MEST-2 showed that the epitope required for binding of this Mab with glucosylceramide would involve the $\beta$-D-Glc residue and the 2-hydroxyl group of the fatty acid from the ceramide portion of the GlcCer (Toledo et al., 2001).

\section{NEW APPLICATIONS IN THE MASS SPECTROMETRIC ANALYSIS OF CEREBROSIDES \\ THIN-LAYER CHROMATOGRAPHY-IONIZATION ORTHOGONAL} TIME-OF-FLIGHT MASS SPECTROMETRY-MASS SPECTROMETRY

With the recent development of ambient MS, the lipids from different sources have been analyzed by HPTLC, and then subjected to MS using desorption techniques, such as DESI and MALDI. The coupling of complementary techniques as TLC and MS could open new avenues for knowledge of specific structural information using trace amounts of fungal glycosphingolipids.

Using the TLC overlay assay, combined with infrared matrixassisted laser desorption/ionization orthogonal time-of-flight mass spectrometry (IR-MALDI-O-TOF-MS), Müsken et al. (2010) carried out the structural characterization of globoseries neutral GSLs (microbial GSL-receptor), recognized by Pfimbriated Escherichia coli, the agent of upper urinary tract infections in humans. The method could be applicable for any GSLbinding non-pathogenic and/or pathogenic E. coli strain, or other microbes such as Helicobacter pylori or viruses. A detailed survey of methodological aspects of this technique is available in the comprehensive review by Meisen et al. (2011).
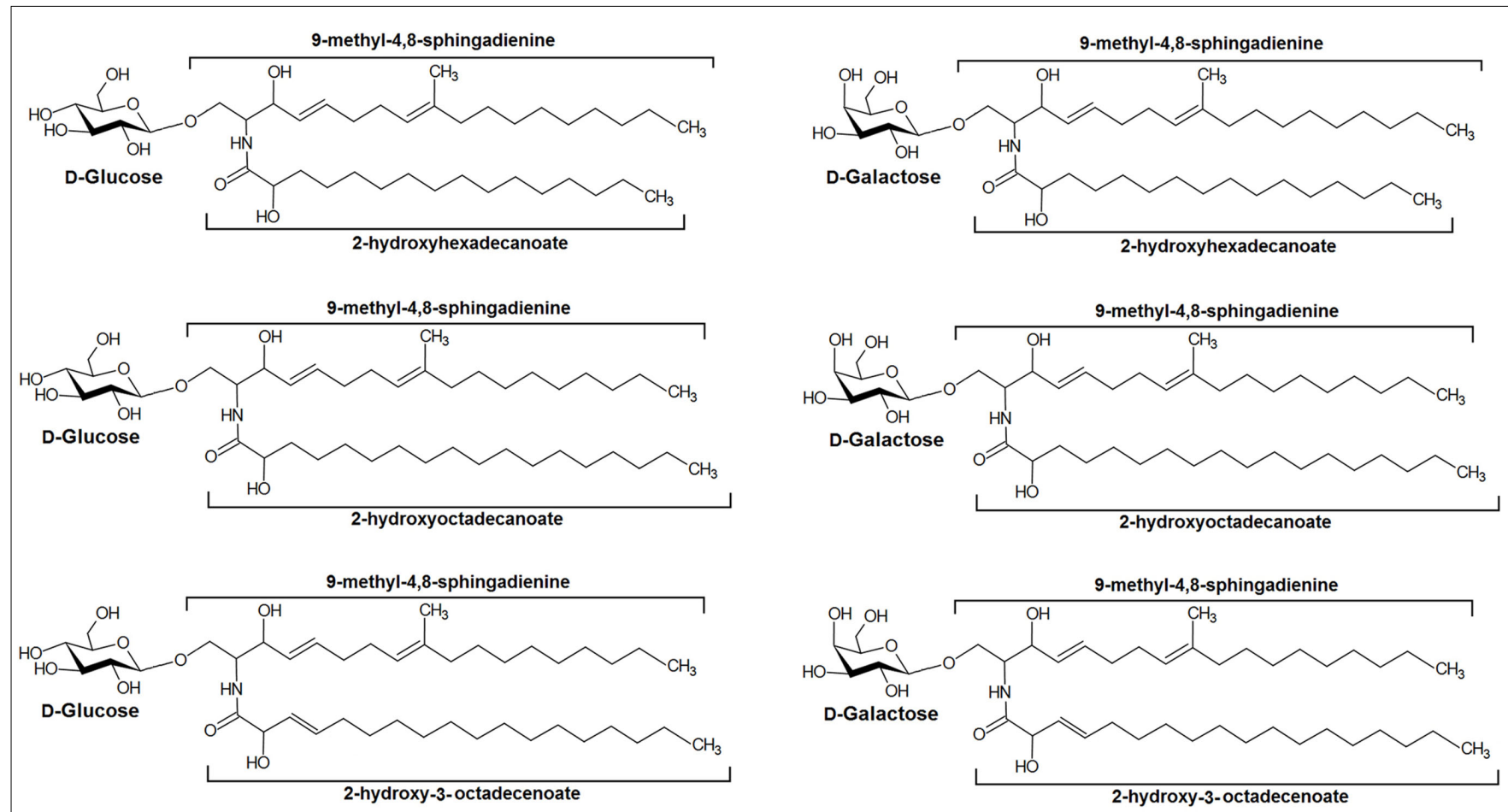

FIGURE 8 | Main structures of cerebrosides isolated from pathogenic fungi. 
This new methodology was successfully applied to the identification of cancer-associated GSLs in several types of human tumors (Müthing and Distler, 2010).

\section{IMAGING MASS SPECTROMETRY}

Current techniques used to identify and quantify glycosphingolipids require a prior extraction and their removal from biological material (cells, tissues) resulting in a loss of information.

Direct tissue analysis and imaging MS are emerging technologies that can help in answering questions raised by current analytical techniques. The subcellular localization and distribution of glycosphingolipids are now beginning to be probed directly using secondary ion mass spectrometry (SIMS) and MALDI techniques (reviewed by Haynes et al., 2009).

In MALDI-MS, the surface of a sample is coated with a matrix which serves to absorb the laser beam, and then volatilize and ionize the sample. For SIMS, the sample is directly desorbed by a primary ion bombardment. A simultaneous acquisition of a large number of biological compounds in mixtures, with the excellent sensitivity obtained by ToF mass analyzer, are the advantages of these techniques, when compared with others using chemical imaging (reviewed by Touboul et al., 2011).

\section{REFERENCES}

Ann, Q., and Adams, J. (1992). Structure determination of ceramides and neutral glycosphingolipids by collisional activation of $[\mathrm{M}+\mathrm{Li}]^{+}$ ions. J. Am. Soc. Mass Spectrom. 3, 260-263.

Ann, Q., and Adams, J. (1993). Structure specific collision induced fragmentations of ceramides cationized with alkali metal ions. Anal. Chem. 65, 7-13.

Arigi, E., Singh, S., Kahlili, A. H., Winter, H. C., Goldstein, I. J., and Levery, S. B. (2007). Characterization of neutral and acidic glycosphingolipids from the lectinproducing mushroom, Polyporus squamosus. Glycobiology 17, 754-766.

Ballio, A., Casinovi, C. G., Framondino, M., Marino, G., Nota, G., and Santurbano, B. (1979). A new cerebroside from Fusicoccum amygdali Del. Biochem. Biophys. Acta 573, 51-60.

Barber, M., Bordoli, R. S., Garner, G. V., Gordon, D. B., Sedgwick, R. D., Tetler, L. W., and Tyler, A. N. (1981a). Fast-atom-bombardment mass spectra of enkephalins. Biochem. J. 197, 401-404.

Barber, M., Bordoli, R. S., Sedgwick, R. D., Tyler, A. N., and Bycroft, B. W. (1981b). Fast atom bombardment mass spectrometry of bleomycin A2 and B2 and their metal complexes. Biochem. Biophys. Res. Commun. 101, 632-638.

Barreto-Bergter, E., Pinto, M. R., and Rodrigues, M. L. (2004). Structure and biological functions of fungal cerebrosides. An. Acad. Bras. Cienc. $76,67-84$.

Batrakov, S. G., Konova, I. V., Sheichenko, V. I., Esipov, S. E., Galanina, L. A., and Istratova, L. N. (2002) Unusual fatty acid composition of cerebrosides from the filamentous soil fungus Mortierella alpina. Chem. Phys. Lipids 117, 45-51. Hartmann, R., and Bergter, E. B. (1994). Structural determination of N-2'-hydroxyoctadecenoyl-1-Obeta-D-glucopyranosyl-9-methyl4,8-sphingadienine from species of Aspergillus. Chem. Phys. Lipids 70, 11-19.

da Silva, A. F., Rodrigues, M. L., Farias, S. E., Almeida, I. C., Pinto, M. R., and Barreto-Bergter, E. (2004). Glucosylceramides in Colletotrichum gloeosporioides are involved in the differentiation of conidia into mycelial cells. FEBS Lett. 561, 137-143.

da Silva, M. C. F., Vieira, R. P., Hartmann, R., Mulloy, B., and BarretoBergter, E. (1997). The structures of polysaccharides and glycolipids of Aspergillus fumigatus grown in the presence of human serum. Mycopathologia 137, 17-25.

Domon, B., and Costello, C. E. (1988). Structure elucidation of glycosphingolipids and gangliosides using high-performance tandem mass spectrometry. Biochemistry 27, 1534-1543.

Duarte, R. S., Polycarpo, C. R., Wait, R., Hartmann, R., and Bergter, E. B.
Boas, M. H., Egge, H., Pohlentz, G.,

\section{CONCLUSION}

This review summarizes classical analytical techniques used for the identification and structural determination of fungal cerebrosides. MS has emerged as a powerful technique for the analysis of cerebrosides, including analytical variations as $\mathrm{FAB} / \mathrm{MS}$, ESI-MS, and low energy ESI-MS/CID-MS. ${ }^{1} \mathrm{H}$ and ${ }^{13} \mathrm{C}$-NMR have also been successfully used in cerebroside structural analysis. The combination of these techniques is usually sufficient for a complete structural elucidation. A detailed structural information of fungal cerebrosides is required in order to elucidate the biological role of these molecules. Also discussed here are some emerging techniques as TLC-IRMALDI-MS and imaging MS in the analysis of glycosphingolipids.

\section{ACKNOWLEDGMENTS}

The authors thank Prof. P. A. J. Gorin for critical reading of this manuscript. This study was supported by grants from the Conselho Nacional de Desenvolvimento Científico e Tecnológico (CNPq), Fundação de Amparo a Pesquisa do Estado do Rio de Janeiro (FAPERJ), PRONEX, and Coordenação de Aperfeiçoamento de Pessoal de Nível Superior (CAPES).

(1998). Structural characterization of neutral glycosphingolipids from Fusarium species. Biochim. Biophys. Acta 1390, 186-196.

Fogedal, M., Mickos, H., and Norberg, T(1986). Isolation of of $\mathrm{N}-2^{\prime}$-hydroxydecanoyl-1-O- $\beta$ D-glucopyranosyl-9-methyl-4,8-Derythro-sphingadienine from fruiting bodies of two Basidiomycetes fungi. Glycoconj. J. 3, 233-237.

Folch, J., Lees, M., and Sloane Stanley, G. H. (1957). A simple method for the isolation and purification of total lipids from animal tissues. J. Biol. Chem. 226, 497-509.

Fujino, Y., and Ohnishi, M. (1976). Structure of cerebroside in Aspergillus oryzae. Biochim. Biophys. Acta 486, 161-171.

Gao, J. M., Hu, L., Dong, Z. J., and Liu, J. K. (2001). New glycosphingolipid containing an unusual sphingoid base from the basidiomycete Polyporus ellisii. Lipids 36, 521-527.

Haynes, C. A., Allegood, J. C., Park, H., and Sullards, M. C. (2009). Sphingolipidomics: methods for the comprehensive analysis of sphingolipids. J. Chromatogr. B Analyt. Technol. Biomed. Life Sci. 877, 2696-2708.

Karas, M., Bachmann, D., Bahr, U., and Hillenkamp, F. (1987). Matrixassisted ultraviolet laser desorption of non-volatile compounds. Int. J. Mass Spectrom. Ion Process. 78, $53 \mathrm{e} 68$.

Karlsson, K. A., and Holm, G. A. (1965). Studies on sphingosines. 9. C19sphingosines, hitherto unknown sphingosines. Acta Chem. Scand. 19, 2423-2425.

Karlsson, K. A., Leffler, H., and Samuelsson, B. E. (1979). Characterization of cerebroside (monoglycosylceramide) from the sea anemone, Metridium senile. Identification of the major long-chain base as an unusual dienic base with a methyl branch at a double bond. Biochim. Biophys. Acta 574, 79-93.

Kates, M. (1986). "Separation of lipid mixtures," in Techniques of Lipidology: Isolation, Analysis and Identification of Lipids, eds $\mathrm{R}$. H. Burdon and P. H. van Knippenberg (Amsterdam: Elsevier), 186-278.

Kawai, G. (1989). Molecular species of cerebrosides in fruiting bodies of Lentinus edodes and their biological activity. Biochim. Biophys. Acta 1001, 185-190.

Kawai, G., and Ikeda, Y. (1982). Fruiting-inducing activity of cerebrosides observed with Schizophlyllum commune. Biochim. Biophys. Acta 719, 612-618.

Kawai, G., and Ikeda, Y. (1985). Structure of biologically active and inactive cerebrosides prepared from Schizophyllum commune. J. Lipid Res. 26, 338-343.

Koga, J., Yamauchi, T., Shimura, M, Ogawa, N, Oshima, K., Umemura, K., Kikuchi, M., and Ogasawara, N. (1998). Cerebrosides A and C, sphingolipid elicitors of hypersensitive cell death and phytoalexin accumulation in rice plants. J. Biol. Chem. 273, 31985-31991. 
Lester, R. L., Smith, S. W., Wells, G. B., Rees, D. C., and Angus, W. W. (1974). The isolation and partial characterization of two novel sphingolipids from Neurospora crassa: di(inositolphosphoryl)ceramide and [(gal)3glu]ceramide. J. Biol. Chem. 249, 3388-3394.

Levery, S. B. (2005). Glycosphingolipid structural analysis and glycosphingolipidomics. Meth. Enzymol. 405, 300-369.

Levery, S. B., Momany, M., Lindsey, R., Toledo, M. S., Shayman, J. A., Fuller, M., Brooks, K., Doong, R. L., Straus, A. H., and Takahashi, H. K. (2002). Disruption of the glucosylceramide biosynthetic pathway in Aspergillus nidulans and Aspergillus fumigatus by inhibitors of UDP-Glc: ceramide glucosyltransferase strongly affects spore germination, cell cycle, and hyphal growth. FEBS Lett. 525, 59-64.

Levery, S. B., Toledo, M. S., Doong, R. L., Straus, A. H., and Takahashi, H. K. (2000). Comparative analysis of ceramide structural modification found in fungal cerebrosides by electrospray tandem mass spectrometry with low energy collisioninduced dissociation of $\mathrm{Li}^{+}$adduct ions. Rapid Commun. Mass Spectrom. 14, 551-563.

Lindley, N. D., and Heyderman, M. T. (1985). Alkane utilization by Cladosporium resinae: the importance of extended lag phases when assessing substrate optima. FEMS Microbiol. Ecol. 31, 307-310.

Maciel, D. M., Rodrigues, M. L., Wait, R., Villas Boas, M. H., Tischer, C. A., and Barreto-Bergter, E. (2002). Glycosphingolipids from Magnaporthe grisea cells: expression of a ceramide dihexoside presenting phytosphingosine as the long-chain base. Arch. Biochem. Biophys. 405, 205-213.

Magnani, J. L., Smith, D. F., and Ginsburg, V. (1980). Detection of gangliosides that bind cholera toxin: direct binding of 125I-labeled toxin to thin-layer chromatograms. Anal. Biochem. 109, 399-402.

Matsubara, T., Hayashi, A., Banno, Y., Morita, T., and Nozawa, Y. (1987). Cerebroside of the dimorphic human pathogen, Candida albicans. Chem. Phys. Lipids 43, 1-12.

Meisen, I., Mormann, M., and Müthing, J. (2011). Thin-layer chromatography, overlay technique and mass spectrometry: a versatile triad advancing glycosphingolipidomics. Biochim. Biophys. Acta 1811, 875-896.

Mineki, S., Iida, M., and Tsutsumi, T. (1994). A new cerebroside of the n-alkane-assimilating yeast Candida deformans. J. Ferment. Bioeng. 78, 327-330.

Mizushina, Y., Hanashima, L., Yamaguchi, T., Takemura, M., Sugawara, F., Saneyoshi, M., Matsukage, A., Yoshida, S., and Sakaguchi, K. (1998). A mushroom fruiting bodyinducing substance inhibits activities of replicative DNA polymerases. Biochem. Biophys. Res. Commun. 249, 17-22.

Morris, H. R., Panico, M., Barber, M., Bordoli, R. S., Sedgwick, R. D., and Tyler, A. (1981). Fast atom bombardment: a new mass spectrometric method for peptide sequence analysis. Biochem. Biophys. Res. Commun. 101, 623-631.

Murphy, R. C., Mathews, W. R., Rokach, J., and Fenselau, C. (1982). Comparison of biological-derived and synthetic leukotriene $\mathrm{C} 4$ by fast atom bombardment mass spectrometry. Prostaglandins 23, 201-206.

Müsken, A., Souady, J., Dreisewerd, K., Zhang, W., Distler, U., Peter-Katalinic, J., Miller-Podraza, H., Karch, H., and Müthing, J. (2010). Application of thin-layer chromatography/infrared matrixassisted laser desorption/ionization orthogonal time-of-flight mass spectrometry to structural analysis of bacteria-binding glycosphingolipids selected by affinity detection. Rapid Commun. Mass Spectrom. 24, 1032-1038.

Müthing, J., and Distler, U. (2010). Advances on the compositional analysis of glycosphingolipids combining thin-layer chromatography with mass spectrometry. Mass Spectrom. Rev. 29, 425-479.

Ng, K. H., and Laneelle, M. A. (1977). Lipids of the yeast Hansenula anomala. Biochimie 59, 97-104.

Nimrichter, L., Barreto-Bergter, E., Mendonca-Filho, R. R., Kneipp, L. F., Mazzi, M. T., Salve, P., Farias, S. E., Wait, R., Alviano, C. S., and Rodrigues, M. L. (2004). A monoclonal antibody to glucosylceramide inhibits the growth of Fonsecaea pedrosoi and enhances the antifungal action of mouse macrophages. Microbes Infect. 6, 657-665.

Nimrichter, L., Cerqueira, M. D., Leitao, E. A., Miranda, K., Nakayasu, E. S., Almeida, S. R., Almeida, I. C.,Alviano, C. S., Barreto-Bergter,E, and Rodrigues, M. L. (2005). Structure, cellular distribution, antigenicity, and biological functions of Fonsecaea pedrosoi ceramide monohexosides. Infect. Immun. 73, 7860-7868.
Park, C., Bennion, B., François, I. E. J. A., Ferket, K. K. A., Cammue, B. P. A., Thevissen, K., and Levery, S. B. (2005). Neutral glycolipids of the filamentous fungus Neurospora crassa altered expression in plant defensinresistant mutants. J. Lipid Res. 46, 759-768.

Peng, X., Wang, Y., Sun, K., Liu, P., Yin, X., and Zhu, W. (2011). Cerebrosides and 2-pyridone alkaloids from the halotolerant fungus Penicillium chrysogenum grown in a hypersaline medium. J. Nat. Prod. 74, 1298-1302.

Pinto, M. R., Rodrigues, M. L., Travassos, L. R., Haido, R. M., Wait, R., and Barreto-Bergter, E. (2002). Characterization of glucosylceramides in Pseudallescheria boydii and their involvement in fungal differentiation. Glycobiology 12, 251-260.

Pittenauer, E., and Allmaier, G. (2009a). High-energy collision induced dissociation of biomolecules: MALDITOF/RTOF mass spectrometry in comparison to tandem sector mass spectrometry. Comb. Chem. High Throughput Screen. 12, 137-155.

Pittenauer, E., and Allmaier, G. (2009b). The renaissance of high-energy CID for structural elucidation of complex lipids: MALDI-TOF/RTOF-MS of alkali cationized triacylglycerols. J. Am. Soc. Mass Spectrom. 20, 1037-1047.

Qi, J., Ojika, M., and Sakagami, Y. (2001). Neuritogenic cerebrosides from an edible Chinese mushroom. Part 2: structures of two additional termitomycesphins and activity enhancement of an inactive cerebroside by hydroxylation. Bioorg. Med. Chem. 9, 2171-2177.

Rodrigues, M. L., Travassos, L. R. Miranda, K. R., Franzen, A. J., Rozental, S., de Souza, W., Alviano, C. S., and Barreto-Bergter, E. (2000). Human antibodies against a purified glucosylceramide from Cryptococcus neoformans inhibit cell budding and fungal growth. Infect. Immun. 68 7049-7060.

Sakaki, T., Zahringer, U., Warnecke, D. C., Fahl, A., Knogge, W., and Heinz, E. (2001). Sterol glycosides and cerebrosides accumulate in Pichia pastoris, Rhynchosporium secalis and other fungi under normal conditions or under heat shock and ethanol stress. Yeast 18, 679-695.

Sassaki, G. L., Souza, L. M., Serrato, R. V., Cipriani, T. R., Gorin, P. A., and Iacomini, M. (2008). Application of acetate derivatives for gas chromatography-mass spectrometry: novel approaches on carbohydrates, lipids and amino acids analysis. J. Chromatogr. A 1208 , 215-222.

Sawabe, A., Morita, M., Okamoto, T., and Ouchi, S. (1994). The location of double bonds in a cerebroside from edible fungi (mushroom) estimated by B/E linked scan fast atom bombardment mass spectrometry. Biol. Mass Spectrom. 23, 660-664.

Sawabi, A., Morita, M., Okamoto, T., and Ouchi, S. (1996). Fast atom bombardment mass spectrometry and linked scan analyses at constant $\mathrm{B} / \mathrm{E}$ in the structural characterization of new polyisoprenepolyols isolated from an edible mushroom (Hypsizygus marmoreus). J. Mass. Spectrom. 31, 921-925.

Sawardeker, J,S., Slonecker, J, H., and Jeanes, A. (1965). Quantitative determination of monosaccharides as alditol acetates by gas chromatography. Anal. Chem. 37, 1602-1604.

Scandroglio, F., Loberto, N., Valsecchi, M., Chigorno, V., Prinetti, A., and Sonnino, S. (2009). Thin layer chromatography of gangliosides. Glycoconj. J 26, 961-973.

Seifert, K. A., Hughes, S. J., Boulay, H., and Louis-Seize, G. (2007). Taxonomy, nomenclature and phylogeny of three Cladosporiumlike hyphomycetes, Sorocybe resinae, Seifertia azaleae and the Hormoconis anamorph of Amorphotheca resinae. Stud. Mycol. 58, 235-245.

Svennerholm, L. (1956). The quantitative estimation of cerebrosides in nervous tissue. J. Neurochem. 1, 42-53.

Sweeley, C. C. (1963). Purification and partial characterization of sphingomyelin from human plasma. J. Lipid Res. 4, 402-406.

Takahashi, H. K., Levery, S. B., Toledo, M. S., Suzuki, E., Salyan, M. E., Hakomori, S., and Straus, A. H. (1996). Isolation and possible composition of glucosylceramides from Paracoccidioides brasiliensis. Braz. J. Med. Biol. Res. 29, 1441-1444.

Takakuwa, N., Kinoshita, M., Oda, Y., and Ohnishi, M. (2002). Existence of cerebroside in Saccharomyces kluyveri and its related species. FEMS Yeast Res. 2, 533-538.

Tavares, P. M., Thevissen, K., Cammue, B. P., Francois, I. E., BarretoBergter, E., Taborda, C. P., Marques, A. F., Rodrigues, M. L., and Nimrichter, L. (2008). In vitro activity of the antifungal plant defensin RsAFP2 against Candida isolates and its in vivo efficacy in prophylactic murine models of candidiasis. Antimicrob. Agents Chemother. 52, $4522-4525$. 
Toledo, M. S., Levery, S. B., Straus, A. H., Suzuki, E., Momany, M., Glushka, J., Moulton, J. M., and Takahashi, H. K. (1999). Characterization of sphingolipids from mycopathogens: factors correlating with expression of 2-hydroxy fatty acyl (E)Delta 3-unsaturation in cerebrosides of Paracoccidioides brasiliensis and Aspergillus fumigatus. Biochemistry 38, 7294-7306.

Toledo, M. S., Levery, S. B., Straus, A. H., and Takahashi, H. K. (2000). Dimorphic expression of cerebrosides in the mycopathogen Sporothrix schenckii. J. Lipid Res. 41, 797-806.

Toledo, M. S., Levery, S. B., Suzuki, E., Straus, A. H., and Takahashi, H. K. (2001). Characterization of cerebrosides from the thermally dimorphic mycopathogen Histoplasma capsulatum: expression of 2hydroxy fatty $\mathrm{N}$-acyl (E)-Delta(3)unsaturation correlates with the yeast-mycelium phase transition. Glycobiology 11, 113-124.
Touboul, D., Brunelle, A., and Laprévote, O. (2011). Mass spectrometry imaging: towards a lipid microscope. Biochimie 93, 113-119

Umemura, K., Ogawa, N., Yamauchi, T., Iwata, M., Shimura, M., and Koga, J. (2000). Cerebroside elicitors found in diverse phytopathogens activate defense responses in rice plants. Plant Cell Physiol. 41, 676-683.

Wagner, H., and Zofcsik, W. (1966). On new sphingolipids of yeast. Biochem. Z. 344, 314-316.

Wang, W., Wang, Y., Tao, H., Peng, X., Liu, P., and Zhu, W. (2009). Cerebrosides of the halotolerant fungus Alternaria raphani isolated from a sea salt field. J. Nat. Prod. 72, 1695-1698.

Warnecke, D., and Heinz, E. (2003). Recently discovered functions of glucosylceramides in plants and fungi. Cell. Mol. Life Sci. 60, 919-941.

Weiss, B., and Stiller, R. L. (1972). Sphingolipids of mushrooms. Biochemistry 11, 4552-4557.
Wells, M. A., and Dittmer, J. C. (1965). A preparative method for the isolation of brain cerebrosides, sulfatide and sphingomyelin. J. Chromatogr. 18, 503-511.

Yamashita, M., and Fenn, J. B. (1984). Electrospray ion source. Another variation on the free-jet theme. $J$. Phys. Chem. 88, 4451-4459.

Zanetta, J. P., Timmerman, P., and Leroy, Y. (1999). Determination of constituents of sulphated proteoglycans using a methanolysis procedure and gas chromatography/mass spectrometry of heptafluorobutyrate derivatives. Glycoconj. J. $16,617-627$.

Zaüner, S., Zähringer, U., Lindner, B., Warnecke, D., and Sperling, P. (2008). Identification and functional characterization of the 2-hydroxy fatty $\mathrm{N}$-acyl-(3(E)-desaturase from Fusarium graminearum. J. Biol. Chem. 283, 36734-36742.

Conflict of Interest Statement: The authors declare that the research was conducted in the absence of any commercial or financial relationships that could be construed as a potential conflict of interest.

Received: 14 September 2011; accepted: 13 November 2011; published online: 05 December 2011.

Citation: Barreto-Bergter E, Sassaki GL and de Souza LM (2011) Structural analysis of fungal cerebrosides. Front. Microbio. 2:239. doi: 10.3389/fmicb.2011.00239

This article was submitted to Frontiers in Fungi and Their Interactions, a specialty of Frontiers in Microbiology.

Copyright (C) 2011 Barreto-Bergter, Sassaki and de Souza. This is an open-access article distributed under the terms of the Creative Commons Attribution Non Commercial License, which permits non-commercial use, distribution, and reproduction in other forums, provided the original authors and source are credited. 